\title{
Sooting tendencies of terpenes and hydrogenated terpenes as sustainable transportation biofuels
}

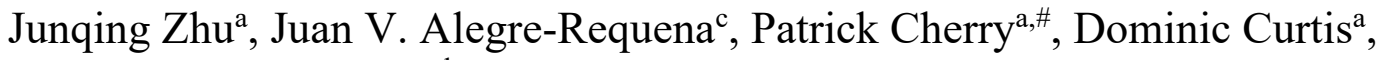 \\ Benjamin G. Harvey ${ }^{\mathrm{b}}$, Mohamed A. Jabed ${ }^{\mathrm{c}}$, Seonah Kimc, Charles S. \\ McEnally $^{\mathrm{a}, *}$, Lisa D. Pfefferle ${ }^{\mathrm{a}}$, Josanne-Dee Woodroffe ${ }^{\mathrm{b}}$ \\ ${ }^{a}$ Department of Chemical and Environmental Engineering, Yale University, New Haven CT 06520 USA \\ ${ }^{b}$ Research Department, Chemistry Division, US Navy, NAWCWD, China Lake CA 93555 USA \\ ${ }^{c}$ Department of Chemistry, Colorado State University, Fort Collins CO 80523 USA
}

\begin{abstract}
Terpenes are a diverse group of molecules that are synthesized by plants and microorganisms through combining units of isoprene (2-methyl-1,3-butadiene). They typically contain rings and methyl branches, which gives them high energy densities and low freezing points and makes them appealing candidates for sustainable transportation biofuels. Between the original biosynthesis and upgrading options such as hydrogenation, they have a large degree of freedom of structures, e.g., different carbon skeletons, positions of double bonds, and functional groups. Therefore, structure-property data is needed to downselect potential fuel candidates. Here, we measured the sooting tendencies of $17 \mathrm{C} 10$ monoterpenes and 7 of their hydrogenated analogues. The hydrogenated compounds were custom synthesized, so the quantities were too small for conventional smoke point measurements. Thus, the sooting tendencies were quantified with yield sooting index (YSI), which is based on the soot yield in a fuel-doped nonpremixed methane flame. Derived smoke points (DSPs) were estimated from a correlation between YSI and smoke point for other hydrocarbons. The YSI of terpenes and their derivatives varies widely from 85.6 to 248.5. The YSI follows the trend: terpenes $>$ dihydroterpenes $>$ tetrahydroterpenes. The DSPs of all the tetrahydroterpenes and some dihydroterpenes are higher than that of a Jet-A fuel sample, suggesting that they offer soot reduction benefits. The YSIs depend strongly on molecular structure; for example, $\alpha$-pinene and $\beta$-pinene have identical carbon skeletons and differ only in the position of one carbon-carbon double bond, but the YSI of $\alpha$-pinene is $34 \%$ higher than that of $\beta$-pinene. Detailed decomposition analysis via density functional theory (DFT) suggests that compared with $\beta$-pinene, $\alpha$-pinene requires fewer steps to form the first aromatic ring and the process is more thermodynamically favorable. The YSI difference between the pinenes is mainly affected by the identity of the products from the dominant decomposition pathways.
\end{abstract}

Keywords: terpene biofuels; sustainable aviation fuels; low-soot fuels; climate change from aviation; yield sooting index (YSI).

*Corresponding author. Email address: charles.mcenally@yale.edu (C. McEnally)

${ }^{\#}$ Currently at Amogy Inc., Brooklyn NY 11205 USA 


\section{Introduction}

Terpenes and their derivatives are a diverse family of biological molecules that provide a rich chemical space for finding renewable fuels with superior properties. Plants and microorganisms synthesize terpenes by combining units of isoprene (2-methyl-1,3-butadiene). Products made from one isoprene (hemiterpenes; C5) are suitable as gasoline alternatives, while products from two isoprenes (monoterpenes; C10) and three isoprenes (sesquiterpenes; C15) can replace jet fuels and diesel fuels. Proposals for large-scale production of terpenes include harvesting them from agricultural crops or from microorganisms growing in bioreactors [1-3]. The compartmentalized nature of terpene biosynthesis provides opportunity to genetically engineer favored organisms such as Eucalyptus or E. coli to make any desired terpene, and to metabolically engineer yields that are beyond the natural baseline $[4,5]$. The branched structure of isoprene causes most terpenes to have methyl side chains, which promotes favorable cold-weather properties such as low melting points [6]. The biosynthesis process readily produces rings, including strained rings with carbon numbers as low as three, which gives terpenes high energy densities $[6,7]$. The bio-synthesis process can also functionalize the terpenes by adding hydroxyl groups, carbonyls, ether bridges, etc. (These molecules are often termed terpenoids, but we will include them with terpenes.) For some applications, especially current aviation engines, oxygen and double bonds are not acceptable since they compromise energy density and storage stability; therefore terpenes must be hydrogenated to saturated hydrocarbons before they can be used as fuels [6]. However, other cases may be less restrictive; for example, the hemiterpene prenol (3-methyl-2-buten-1-ol) is being investigated as a gasoline blendstock due to its high octanesensitivity and synergistic blending behavior for octane number [8].

An increasingly important property of fuels is sooting tendency. Soot emissions from combustion devices contribute to ambient fine particulates, which cause millions of deaths worldwide each year $[9,10]$, and they are the dominant source of black carbon, which is the second largest cause of global warming [11]. The impact of soot on climate change is particularly pronounced in aviation: not only is the radiative forcing (RF) from aviation-generated black carbon almost one-third that of aviationemitted $\mathrm{CO}_{2}$ (9.5 vs. $\left.35 \mathrm{~mW} / \mathrm{m}^{2}[12,13]\right)$, but soot particles are the primary nucleation source for aviation-induced cirrus (AIC), which has the largest $\mathrm{RF}$ due to aviation $\left(50 \mathrm{~mW} / \mathrm{m}^{2}\right.$ [12]). Experiments with aircraft flying in tandem have demonstrated that contrail formation from the lead plane is reduced if it is burning sustainable aviation fuels (SAFs) with low aromatics content [14].

The sootiness of terpenes relative to conventional jet fuel is not obvious: terpenes are usually not aromatic and they often contain oxygen, which can suppress soot formation [15], but they also contain structural features that enhance soot formation such as double bonds and rings [16]. Donoso et al. have demonstrated that turpentine-derived terpene mixtures can have lower sooting tendencies than conventional jet fuel, and that hydrogenating them reduces sooting tendency further [2]. Zschocke et al. have shown that adding the hydrogenated analogue of the sesquiterpene farnesane $(2,6,10$-trimethyldodecane) to Jet A-1 reduces sooting tendency [17].

The objective of this study is to systematically investigate the sooting behavior of terpenes and their hydrogenated analogues. Sooting tendencies were measured with a yield-based approach we developed recently [18], which offers several benefits compared to other approaches such as smoke point (SP): (1) it requires much smaller sample volumes, $\sim 100 \mu \mathrm{L}$ vs $10 \mathrm{~mL}$ [19]; (2) it has a much wider dynamic range; and (3) the flames can be computationally simulated to test kinetic mechanisms and develop insight into the soot formation chemistry [20]. The first benefit was critical to this study since the hydrogenated terpenes had to be custom synthesized. However, since SP is used as the sooting tendency metric in the ASTM standards for petroleum-derived aviation fuels [19] and synthetic aviation fuels [21], we derived a correlation between YSI and SP, and used it to estimate derived smoke points (DSP) for the terpenes. We also performed density functional theory (DFT) calculations to explain some of the differences observed in YSI.

\section{Materials and Procedures}

\subsection{Reactants and Synthesis}

Supplemental Information (SI) A lists the sources and purities of all the samples tested in this study. Most were purchased from commercial vendors while some were custom-synthesized. The details of synthesis are described in [22] for PN, LMA, and THSB; [23] for DHSB, DHCR, and THCR; and [24] for DMCO. POSF10325 is a conventional petroleum-derived Jet-A fuel with average/nominal values of flash point, viscosity, and aromatics content [25]. 


\subsection{Sooting tendency measurements}

Sooting tendencies were measured using a yieldbased approach we developed previously [18]. The procedure used in this study is described in [26].

It consists of three steps: (1) we sequentially doped $1000 \mathrm{ppm}(1000 \mu \mathrm{mol} / \mathrm{mol})$ of $\mathrm{n}$-heptane (HEP), toluene (TOL), and each test sample (TS) into the fuel of a base methane/air flame; (2) we measured the maximum soot concentration in each flame with line-of-sight spectral radiance (LSSR); and (3) we rescaled the results into a yield sooting index (YSI) defined as:

$$
\begin{aligned}
\mathrm{YSI}_{\mathrm{TS}}= & \left(\mathrm{YSI}_{\mathrm{TOL}}-\mathrm{YSI}_{\mathrm{HEP}}\right) \times \frac{\mathrm{LSSR}_{\mathrm{TS}}-\mathrm{LSSR}_{\mathrm{HEP}}}{\mathrm{LSSR}_{\mathrm{TOL}}-\mathrm{LSSR}_{\mathrm{HEP}}} \\
& +\mathrm{YSI}_{\mathrm{HEP}}
\end{aligned}
$$

This rescaling method factors out sources of systematic uncertainty such as errors in the gasphase reactant flowrates. Furthermore, it allows the new results to be quantitatively compared with a database that contains measured YSIs for hundreds of organic compounds [27]. The parameters $\mathrm{YSI}_{\mathrm{TOL}}$ and $\mathrm{YSI}_{\mathrm{HEP}}$ are constants that define the YSI scale; their values - 170.9 and 36.0 - were taken from the database so that the newly measured YSIs would be on the same scale for a direct comparison. SI B lists the liquid-phase flowrates corresponding to 1000 $\mathrm{ppm}$ in the gas-phase for each TS, and the property values $[25,28-30]$ used to calculate them. SI C shows a schematic diagram of the LSSR apparatus and SI D gives details of the specific burner [31]. Isooctane was included in each measurement set as an internal standard; SI F shows that the values were consistent over time and agreed with previous measurements. SI G shows that the LSSR signals of several low volatility compounds increased linearly with the dopant mole fraction, which confirms that they vaporized readily and the signal response of the optical apparatus was in a linear regime.

\subsection{Density functional theory calculation}

$(D F T)$

Quantum mechanical calculations were carried out with the Gaussian 16 program in the gas phase [32]. Geometry optimizations along the reaction pathways were conducted with the M06-2X density functional [33] and the def2-TZVP basis set [34, 35]. Gibbs free energy values were refined with quasi-harmonic (QHA) vibrational corrections to entropy using the GoodVibes program [36] at $1500 \mathrm{~K}$. For more details, see SI H [37-43].

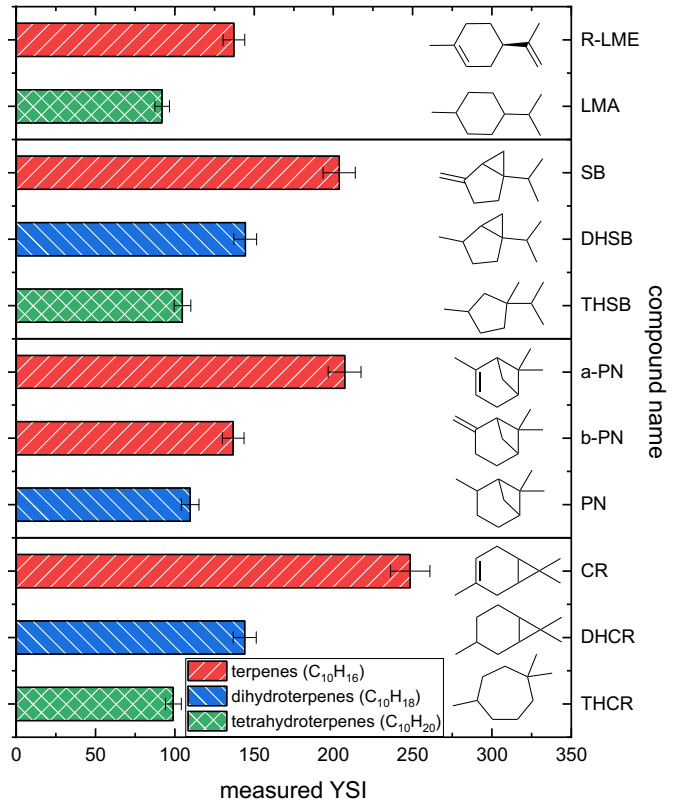

Fig. 1. Measured YSIs of terpenes, dihydroterpenes, and tetrahydroterpenes.

\section{Results and discussion}

\subsection{YSI of terpenes}

Table 1 lists the YSIs measured for the terpenes, hydrogenated terpenes, and the Jet-A sample. Larger YSIs indicate sootier fuels.

Each YSI was measured three times and then averaged. The systematic uncertainty in YSI is \pm $2 \%$, which is dominated by the uncertainty in the mass densities of the samples. The random uncertainty is $\pm 4 \%$, which is 2 times the standard deviation of the 26 measurements of the internal standard (SI F). Therefore, the overall uncertainty of the measured YSIs is $\pm 6 \%$.

Fig. 1 shows the measured YSIs of several terpenes and the corresponding hydrogenated terpenes with two hydrogen atoms added (dihydroterpenes) and four hydrogen atoms added (tetrahydroterpenes). In each case the YSI decreases from the original terpenes to the dihydroterpenes, and then some more to the tetrahydroterpenes. Therefore, hydrogenation of the $\mathrm{C}=\mathrm{C}$ bonds (terpene $\rightarrow$ dihydroterpene) both mitigates soot and improves oxidative stability [6]. Hydrogenation of rings (dihydroterpene $\rightarrow$ tetrahydroterpene) also mitigates soot but potentially lowers the gravimetric energy density associated with the ring strain. 
Table 1

Measured YSIs and calculated DSPs of Jet-A, terpenes, and hydrogenated terpenes.

\begin{tabular}{|c|c|c|c|c|c|}
\hline Name & Abbr. & Structure & SMILES & $\mathrm{YSI}^{\mathrm{a}}$ & $\begin{array}{l}\mathrm{DSP} \\
(\mathrm{mm})\end{array}$ \\
\hline \multicolumn{6}{|c|}{ Endpoints, Internal Standard, and Jet-A } \\
\hline $\begin{array}{c}\text { n-heptane } \\
\text { (lower endpoint) }\end{array}$ & HEP & & $\mathrm{CCCCCCC}$ & $\begin{array}{l}36.0 \\
{[27]}\end{array}$ & 119.8 \\
\hline $\begin{array}{c}\text { toluene } \\
\text { (upper endpoint) }\end{array}$ & TOL & & $\mathrm{Cc} 1 \mathrm{ccccc} 1$ & $\begin{array}{c}170.9 \\
{[27]}\end{array}$ & 8.6 \\
\hline $\begin{array}{c}\text { isooctane } \\
\text { (internal standard) }\end{array}$ & ISO & & $\mathrm{CC}(\mathrm{C}) \mathrm{CC}(\mathrm{C})(\mathrm{C}) \mathrm{C}$ & 64.1 & 47.3 \\
\hline POSF10325 & Jet-A & not applicable & not applicable & 150.0 & 21.3 \\
\hline \multicolumn{6}{|c|}{ Terpenes and hydrogenated terpenes } \\
\hline R-limonene & R-LME & & $\mathrm{C}=\mathrm{C}(\mathrm{C})[\mathrm{C} @ \mathrm{H}] 1 \mathrm{CC}=\mathrm{C}(\mathrm{C}) \mathrm{CC} 1$ & 137.3 & 18.7 \\
\hline limonane & LMA & & $\mathrm{CC} 1 \mathrm{CCC}(\mathrm{C}(\mathrm{C}) \mathrm{C}) \mathrm{CC} 1$ & 92.0 & 35.6 \\
\hline sabinene & SB & & $\mathrm{C}=\mathrm{C} 1 \mathrm{CCC} 2(\mathrm{C}(\mathrm{C}) \mathrm{C}) \mathrm{CC} 12$ & 203.7 & 11.6 \\
\hline dihydrosabinene ${ }^{b}$ & DHSB & & $\mathrm{CC} 1 \mathrm{CCC} 2(\mathrm{C}(\mathrm{C}) \mathrm{C}) \mathrm{CC} 12$ & 144.5 & 18.4 \\
\hline tetrahydrosabinene ${ }^{\mathrm{b}}$ & THSB & & $\mathrm{CC} 1 \mathrm{CCC}(\mathrm{C} 1)(\mathrm{C}) \mathrm{C}(\mathrm{C}) \mathrm{C}$ & 104.9 & 29.4 \\
\hline$\alpha$-pinene & $\mathrm{a}-\mathrm{PN}$ & & $\mathrm{CC} 1=\mathrm{CCC} 2 \mathrm{CC} 1 \mathrm{C} 2(\mathrm{C}) \mathrm{C}$ & 207.1 & 11.4 \\
\hline$\beta$-pinene & b-PN & & $\mathrm{CC} 1(\mathrm{C}) \mathrm{C} 2 \mathrm{CCC}(\mathrm{C} 1 \mathrm{C} 2)=\mathrm{C}$ & 136.9 & 18.8 \\
\hline pinane & $\mathrm{PN}$ & & $\mathrm{CC} 1 \mathrm{CCC} 2 \mathrm{CC} 1 \mathrm{C} 2(\mathrm{C}) \mathrm{C}$ & 109.7 & 26.4 \\
\hline 3 -carene & $\mathrm{CR}$ & & $\mathrm{CC} 1=\mathrm{CCC} 2 \mathrm{C}(\mathrm{C} 1) \mathrm{C} 2(\mathrm{C}) \mathrm{C}$ & 248.5 & 9.2 \\
\hline dihydrocarene $\mathrm{e}^{\mathrm{b}}$ & DHCR & & $\mathrm{CC} 1 \mathrm{CCC} 2 \mathrm{C}(\mathrm{C} 1) \mathrm{C} 2(\mathrm{C}) \mathrm{C}$ & 144.1 & 18.4 \\
\hline tetrahydrocarene ${ }^{\mathrm{b}}$ & THCR & & $\mathrm{CC} 1 \mathrm{CCCC}(\mathrm{C})(\mathrm{C}) \mathrm{CC} 1$ & 99.1 & 31.9 \\
\hline 1,4-dimethylcyclooctane & DMCO & & $\mathrm{CC} 1 \mathrm{CCCCC}(\mathrm{C}) \mathrm{CC} 1$ & 84.7 & 40.4 \\
\hline 1,8 -cineole & $18 \mathrm{CL}$ & & $\mathrm{CC} 1(\mathrm{C} 2 \mathrm{CCC}(\mathrm{O} 1)(\mathrm{CC} 2) \mathrm{C}) \mathrm{C}$ & 111.0 & 24.7 \\
\hline 1,4-cineole & $14 \mathrm{CL}$ & & $\mathrm{CC}(\mathrm{C}) \mathrm{C} 12 \mathrm{CCC}(\mathrm{O} 1)(\mathrm{CC} 2) \mathrm{C}$ & 104.6 & 26.8 \\
\hline S-carvone & $\mathrm{S}-\mathrm{CV}$ & & $\mathrm{CC} 1=\mathrm{CC}[\mathrm{C} @ @ \mathrm{H}](\mathrm{CC} 1=\mathrm{O}) \mathrm{C}(=\mathrm{C}) \mathrm{C}$ & 126.4 & 18.9 \\
\hline R-carvone & $\mathrm{R}-\mathrm{CV}$ & & $\mathrm{CC} 1=\mathrm{CC}[\mathrm{C} @ \mathrm{H}](\mathrm{CC} 1=\mathrm{O}) \mathrm{C}(=\mathrm{C}) \mathrm{C}$ & 127.7 & 18.7 \\
\hline myrcene & MC & & $\mathrm{CC}(=\mathrm{CCCC}(=\mathrm{C}) \mathrm{C}=\mathrm{C}) \mathrm{C}$ & 103.6 & 27.2 \\
\hline$\beta$-ocimene & $\mathrm{b}-\mathrm{OM}$ & & $\mathrm{CC}(=\mathrm{CCC}=\mathrm{C}(\mathrm{C}) \mathrm{C}=\mathrm{C}) \mathrm{C}$ & 213.6 & 11.0 \\
\hline dihydromyrcene & DHMC & & $\mathrm{CC}(\mathrm{C}=\mathrm{C}) \mathrm{CC} / \mathrm{C}=\mathrm{C}(\mathrm{C}) \backslash \mathrm{C}$ & 110.9 & 26.0 \\
\hline geranial & GNA & & $\mathrm{CC}(=\mathrm{CCCC}(=\mathrm{CC}=\mathrm{O}) \mathrm{C}) \mathrm{C}$ & 91.8 & 30.6 \\
\hline
\end{tabular}




\begin{tabular}{|l|l|l|l|l|l|}
\hline geraniol & $\mathrm{GNO}$ & $\mathrm{CC}(=\mathrm{CCCC}(=\mathrm{CCO}) \mathrm{C}) \mathrm{C}$ & 103.7 & 27.2 \\
\hline citronellal & $\mathrm{CTL}$ & $\mathrm{CC}(\mathrm{CCC}=\mathrm{C}(\mathrm{C}) \mathrm{C}) \mathrm{CC}=\mathrm{O}$ & 85.6 & 35.8 \\
\hline carvacrol & $\mathrm{CVC}$ & $\mathrm{CC}=\mathrm{C}(\mathrm{C}=\mathrm{C}(\mathrm{C}=\mathrm{C} 1) \mathrm{C}(\mathrm{C}) \mathrm{C}) \mathrm{O}$ & 193.1 & 11.3 \\
\hline linalool & $\mathrm{LNL}$ & $\mathrm{CC}(=\mathrm{CCCC}(\mathrm{C})(\mathrm{C}=\mathrm{C}) \mathrm{O}) \mathrm{C}$ & 98.0 & 29.4 \\
\hline
\end{tabular}

a The uncertainty is $\pm 6 \%$;

${ }^{\mathrm{b}}$ The YSIs of these compounds were corrected for impurities based on their measured composition in SI A and the assumption that the YSI of a mixture is the mole-fraction-weighted average of the YSIs of each component.

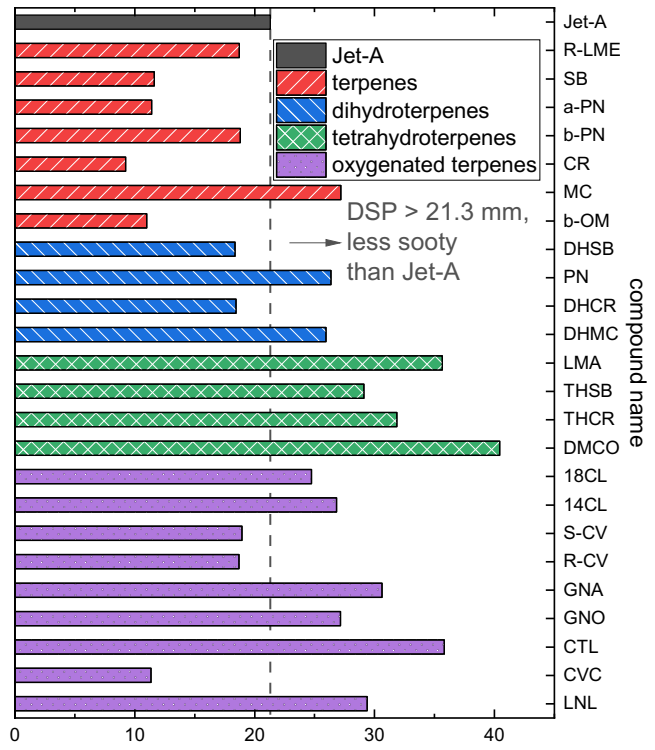

Fig. 3. Derived smoke points (DSPs) of Jet-A, terpenes, and hydrogenated terpenes.

\subsection{DSP of terpenes}

The scaling analysis in SI E indicates that YSI is proportional to $\mathrm{SP} / S$, where $S$ is the moles of oxidizer required to stoichiometrically combust one mole of fuel [44]. The figure in SI E shows that this relationship fits a wide range of pure hydrocarbons and mixtures where both YSI and SP have been measured [2, 19, 25, 27, 45]. Based on the linear least-squares fit to the data in this figure, a derived smoke point (DSP) can be calculated from the measured YSIs with the equation:

$$
\text { DSP }=\frac{30.4}{\frac{\text { YSI }}{\mathrm{S}}-0.427}
$$

DSPs were calculated for each terpene and hydrogenated terpene, as listed in Table 1.

Fig. 2 shows the DSP of Jet-A, terpenes, and hydrogenated terpenes. A higher DSP means a lower sooting tendency. Most of the terpenes are sootier than Jet-A (i.e., have a smaller DSP). On the other hand, some of the dihydroterpenes and all of

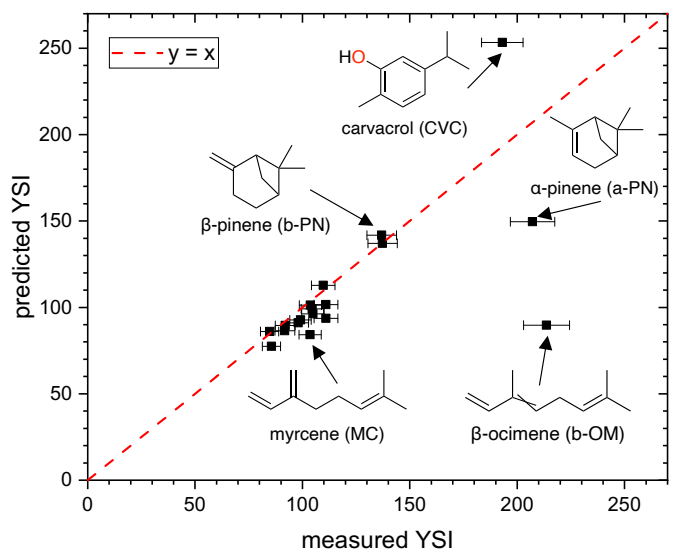

Fig. 2. Predicted YSIs vs measured YSIs of terpenes and hydrogenated terpenes.

the tetrahydroterpenes are less sooty than Jet-A (i.e., have a larger DSP), which means they would likely offer soot reduction benefits as sustainable aviation fuels.

\subsection{Kinetic pathways}

A group contribution model (GCM) [46] was used to predict the YSIs of the terpenes and hydrogenated terpenes. In this model, the sooting tendency of a molecule is calculated as the linear sum of the YSI contributions from each of its component carbon-centered groups. More details about the prediction and the training set are included in SI L. Fig. 3 plots the predicted YSIs against the measured YSIs. The predictions agree reasonably well with the measurements except for three striking outliers: CVC, b-OM, and a-PN. By its nature, the GCM cannot account for non-nearest neighbor interactions (NNNIs); therefore, the observed trend suggests that NNNIs are important for the three outliers, but not the other compounds. Each of these outliers and several related compounds are discussed next.

Carvacrol. CVC is a benzenoid aromatic with a hydroxy group attached to the ring. Its measured YSI (193.1) is much lower than its GCM-predicted YSI (253.3), which suggests it undergoes a NNNI that suppresses soot formation. We have observed similar soot suppression for other alkylphenols, e.g., 


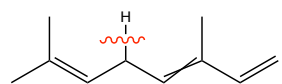

$\beta$-ocimene (b-OM)

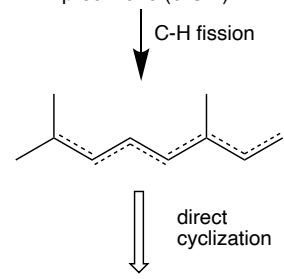

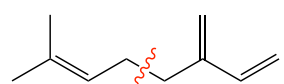

myrcene (MC)

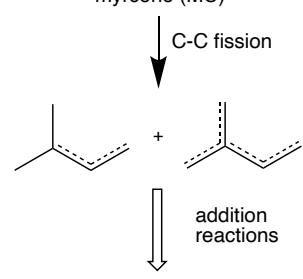

Fig. 4. Proposed kinetic pathways for b-OM and MC.

[47]. The likely mechanism is that $\mathrm{C}-\mathrm{H}$ fission in the hydroxy group produces resonantly-stabilized phenoxy-like radicals that interfere with growth to multi-ring aromatics.

$\beta$-Ocimene. $b-O M$ is a non-cyclic species but it has one of the largest YSIs measured in this study. Its measured YSI (213.6) is much larger than its GCM-predicted YSI (89.6), which suggests it undergoes a NNNI that enhances soot formation. Structurally, it is a substituted 1,4-pentadiene which has two $\mathrm{C}-\mathrm{C}$ single bonds sandwiched between $\mathrm{C}-\mathrm{C}$ double bonds (see the right side of Fig. 4). The C-H bonds on the central carbon are extremely weak $(\mathrm{BDE}=69.2 \mathrm{kcal} / \mathrm{mol}$ [37]) since their fission produces a "triple-allyl" radical with four resonance structures. This highly-conjugated $\mathrm{C} 10$ radical can likely cyclize directly to substituted aromatic hydrocarbons, which provides the soot-enhancing NNNI. Consistent with this hypothesis, we observed larger aromatics production from 1,4-hexadiene than other hexadienes in an earlier mass spectrometry (MS) study of doped flames. Furthermore, we observed very little formation of $\mathrm{C} 3$ and $\mathrm{C} 4$ products from 1,4-hexadiene.

Myrcene. MC is identical to b-OM except for the position of one $\mathrm{C}-\mathrm{C}$ double bond, but it has a much lower YSI (103.9 vs. 213.6). Its measured YSI is reasonably predicted by the GCM (103.9 vs. 84.2), which suggests that it does not experience any NNNIs. Structurally it is a substituted 1,5-hexadiene with three $\mathrm{C}-\mathrm{C}$ single bonds sandwiched between two C-C double bonds (see the left side of Fig. 4). The weakest bond is the central $\mathrm{C}-\mathrm{C}$ bond $(\mathrm{BDE}=$ $62.8 \mathrm{kcal} / \mathrm{mol}$ [37]) since its fission produces two allylic radicals. These radicals only contain five carbon atoms, so they must undergo addition reactions with other species to form benzenoid aromatics, which causes soot production to be slower than in b-OM and other terpenes. This hypothesis is also consistent with our hexadiene study [48], where 1,5-hexadiene produced relatively low concentrations of aromatics but high concentrations of $\mathrm{C} 3$ species. It is also consistent with the flame-flame molecular-beam MS (MBMS)
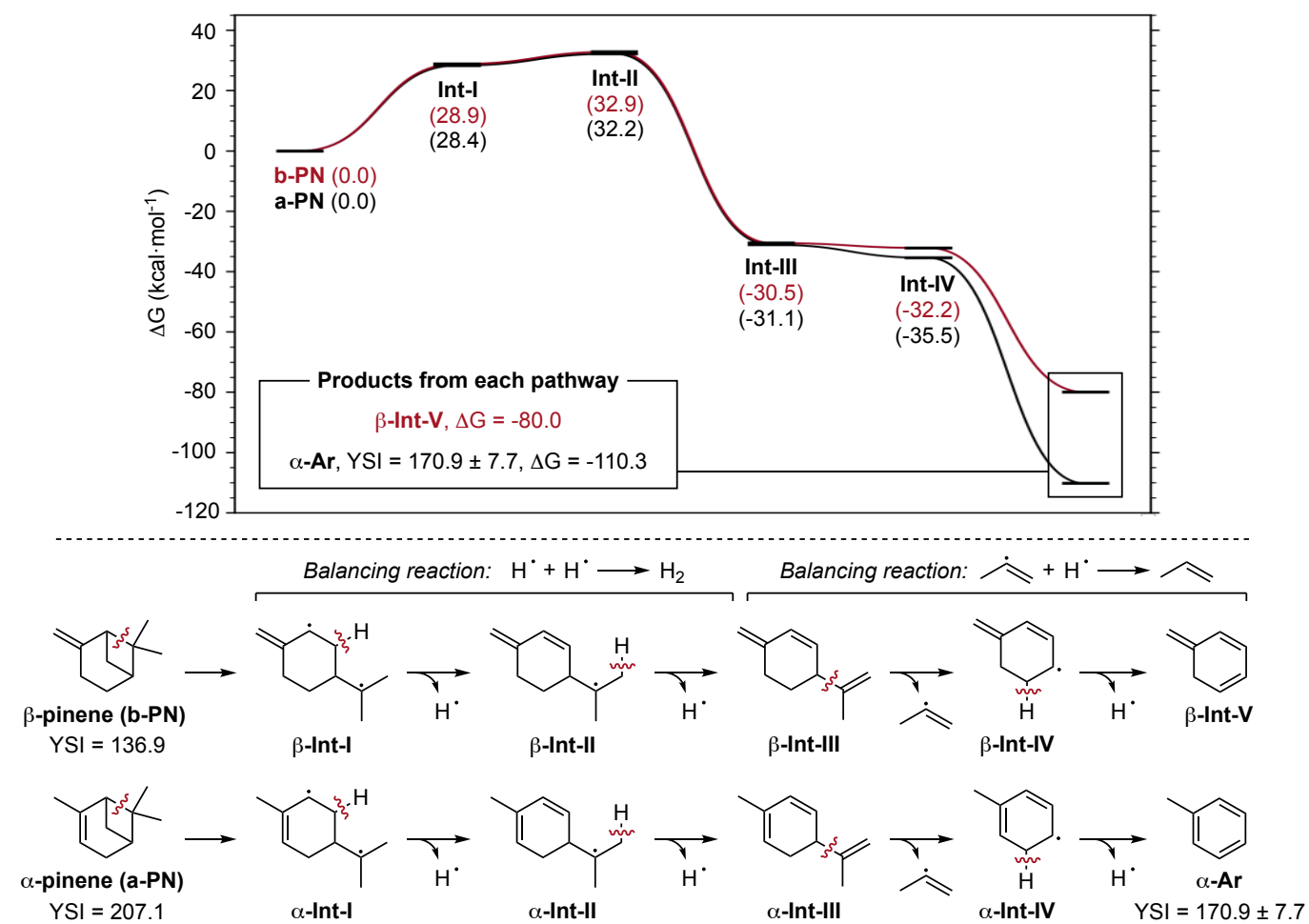

Fig. 4. Decomposition pathways of $\alpha$-pinene (a-PN) and $\beta$-pinene (b-PN) by DFT. Relative Gibbs free energies were obtained with the M06-2X/def2-TZVP level of theory at 1,500 K (applying quasi-harmonic vibrational corrections). Energies of Int-I are shown in triplet state. 
study of Bierkandt et al. [49], where MC produced relatively large amounts of $\mathrm{C} 5$ species.

Pinenes. The two pinene isomers are identical except for the position of one C-C double bond, but they have very different YSIs (207.1 for a-PN vs. 136.9 for b-PN). The measured YSI of a-PN is much larger than its predicted YSI (207.1 vs. 149.6), indicating a soot-enhancing NNNI, while the YSI of b-PN is well-predicted (136.9 vs. 141.8), indicating no NNNI. Theoretical calculations were performed to understand these differences. All the bond dissociation free energies (BDFE) of both molecules were obtained, which showed that opening of the four-membered ring requires less energy than the other dissociating events (SI I [37]). Potential energy surfaces of pathways initiated with the unimolecular ring opening were calculated with DFT. The pathways with the lowest activation barriers are shown in Fig. 5. Relative Gibbs free energy using different levels of theory and analysis of spin contamination are in SI J. Kinetically, low activation barriers (up to $32.9 \mathrm{kcal} \cdot \mathrm{mol}^{-1}$ ) make both pathways favorable. Thermodynamically, the a-PN pathways are more favorable due to a more negative $\Delta \mathrm{G}$ from the formation of more stabilized allyl-type radicals. a-PN forms $\alpha-\mathrm{Ar}$ (toluene) as an aromatic species with a measured YSI of 170.9 while b-PN forms $\beta$-Int-V (5-methylene-1,3-cyclohexadiene) as a non-aromatic species that is likely less sooty than toluene. This difference qualitatively agrees with the YSI difference between a-PN and b-PN. Since more steps are needed for $\beta$-Int-V, the YSI difference between a-PN and b-PN is mainly affected by the identity of the products. SI-K show alternative pathways that compete with those in Fig. 5 but are expected to be less important. A similar conclusion can be drawn that a-PN forms an aromatic species while b-PN forms a non-aromatic species. The YSI of a-PN (207.1) is between that of the product from this pathway (4-Isopropenyltoluene; 389.6), and the product from the main pathway (toluene; 170.9), which further validates these pathways.

\section{Acknowledgements}

The work at Yale was based upon subcontract DE-A36-08GO28308 from the Alliance for Sustainable Energy, LLC, Managing and Operating Contractor for the National Renewable Energy Laboratory (NREL) for DOE. The work at NAWCWD was funded by Office of Naval Research Naval Air Warfare Center, Weapons Division NISE-219 program. Computer time for CSU was provided by the NSF Extreme Science and Engineering Discovery Environment (XSEDE), Grant no. TG-CHE210034 and by the NREL Computational Science Center. Joshua Heyne (University of Dayton) provided the POSF10325 sample from the Air Force Research Laboratory.

\section{Supplementary material}

Supplementary material associated with this article can be found, in the online version, at doi:tobe-filled-in-later.

\section{References}

[1] N.R. Baral, O. Kavvada, D. Mendez-Perez, A. Mukhopadhyay, T.S. Lee, B.A. Simmons, et al., Technoeconomic analysis and life-cycle greenhouse gas mitigation cost of five routes to bio-jet fuel blendstocks, Energy Environ. Sci., 12 (2019) 807-824.

[2] D. Donoso, R. Ballesteros, D. Bolonio, M.-J. GarcíaMartínez, M. Lapuerta, L. Canoira, Hydrogenated Turpentine: A Biobased Component for Jet Fuel, Energy \& Fuels, 35 (2020) 1465-1475.

[3] R. Mewalal, D.K. Rai, D. Kainer, F. Chen, C. Kulheim, G.F. Peter, et al., Plant-Derived Terpenes: A Feedstock for Specialty Biofuels, Trends Biotechnol., 35 (2017) 227240.

[4] J. Keasling, H. Garcia Martin, T.S. Lee, A. Mukhopadhyay, S.W. Singer, E. Sundstrom, Microbial production of advanced biofuels, Nat. Rev. Microbiol., 19 (2021) 701-715.

[5] G. Daletos, C. Katsimpouras, G. Stephanopoulos, Novel Strategies and Platforms for Industrial Isoprenoid Engineering, Trends Biotechnol., 38 (2020) 811-822.

[6] J.-D. Woodroffe, D.V. Lupton, M.D. Garrison, E.M. Nagel, M.J. Siirila, B.G. Harvey, Synthesis and fuel properties of high-energy density cyclopropanated monoterpenes, Fuel Process. Technol., 222 (2021).

[7] X. Zhang, L. Pan, L. Wang, J.-J. Zou, Review on synthesis and properties of high-energy-density liquid fuels: Hydrocarbons, nanofluids and energetic ionic liquids, Chem. Eng. Sci., 180 (2018) 95-125.

[8] E. Monroe, J. Gladden, K.O. Albrecht, J.T. Bays, R. McCormick, R.W. Davis, et al., Discovery of novel octane hyperboosting phenomenon in prenol biofuel/gasoline blends, Fuel, 239 (2019) 1143-1148.

[9] C.J.L. Murray, A.Y. Aravkin, P. Zheng, C. Abbafati, K.M. Abbas, M. Abbasi-Kangevari, et al., Global burden of 87 risk factors in 204 countries and territories, 19902019: a systematic analysis for the Global Burden of Disease Study 2019, The Lancet, 396 (2020) 1223-1249.

[10] K. Vohra, A. Vodonos, J. Schwartz, E.A. Marais, M.P. Sulprizio, L.J. Mickley, Global mortality from outdoor fine particle pollution generated by fossil fuel combustion: Results from GEOS-Chem, Environ. Res., 195 (2021) 110754.

[11] T.C. Bond, S.J. Doherty, D.W. Fahey, P.M. Forster, T. Berntsen, B.J. DeAngelo, et al., Bounding the role of black carbon in the climate system: A scientific assessment, J. Geophys. Res. Atmos., 118 (2013) 53805552.

[12] B. Karcher, Formation and radiative forcing of contrail cirrus, Nat Commun, 9 (2018) 1824.

[13] M.E. Stettler, A.M. Boies, A. Petzold, S.R. Barrett, Global civil aviation black carbon emissions, Environ Sci Technol, 47 (2013) 10397-10404.

[14] C. Voigt, J. Kleine, D. Sauer, R.H. Moore, T. Bräuer, P. Le Clercq, et al., Cleaner burning aviation fuels can reduce contrail cloudiness, Communications Earth \& Environment, 2 (2021). 
[15] P. Pepiot-Desjardins, H. Pitsch, R. Malhotra, S. Kirby, A. Boehman, Structural group analysis for soot reduction tendency of oxygenated fuels, Combust. Flame, 154 (2008) 191-205.

[16] A. Gomez, G. Sidebotham, I. Glassman, Sooting Behavior in Temperature-Controlled Laminar Diffusion Flames, Combust. Flame, 58 (1984) 45-57.

[17] A. Zschocke, S. Scheuermann, J. Ortner, High biofuel blends in aviation (HBBA), Interim Report, ENER C, 2 (2017) 420-421.

[18] C.S. McEnally, L.D. Pfefferle, Improved sooting tendency measurements for aromatic hydrocarbons and their implications for naphthalene formation pathways, Combust. Flame, 148 (2007) 210-222.

[19] ASTM D1322-19 - Standard Test Method for Smoke Point of Kerosene and Aviation Turbine Fuel, ASTM International, (2019).

[20] H. Kwon, S. Lapointe, K. Zhang, S.W. Wagnon, W.J. Pitz, J. Zhu, et al., Sooting tendencies of 20 bio-derived fuels for advanced spark-ignition engines, Fuel, 276 (2020).

[21] ASTM D7566 - 21 Standard Specification for Aviation Turbine Fuel Containing Synthesized Hydrocarbons, ASTM International, (2021).

[22] J.-D. Woodroffe, B.G. Harvey, High-Performance, Biobased, Jet Fuel Blends Containing Hydrogenated Monoterpenes and Synthetic Paraffinic Kerosenes, Energy \& Fuels, 34 (2020) 5929-5937.

[23] J.-D. Woodroffe, B.G. Harvey, Chemoselective Hydrogenation of Ring - Strained Monoterpenes: A Route to High - Performance Sustainable Aviation Fuels, Energy Technology, 9 (2021).

[24] K.E. Rosenkoetter, C.R. Kennedy, P.J. Chirik, B.G. Harvey, [4+4]-Cycloaddition of Isoprene for the Production of High-Performance Bio-Based Jet Fuel, Green Chem., 21 (2019) 5616-5623.

[25] J.T. Edwards, Reference jet fuels for combustion testing, 55th AIAA aerospace sciences meeting, (2017) 0146

[26] C.S. McEnally, Y. Xuan, P.C. St. John, D.D. Das, A. Jain, S. Kim, et al., Sooting tendencies of co-optima test gasolines and their surrogates, Proc. Combust. Inst, 37 (2019) 961-968.

[27] C.S. McEnally, D.D. Das, L.D. Pfefferle, Yield Sooting Index database volume 2: Sooting tendencies of a wide range of fuel compounds on a unified scale, (2017), https://doi.org/10.7910/DVN/7HGFT8.

[28] DIPPR Project 801 - Full Version, Design Institute for Physical Property Research/AIChE, (2019), https://app.knovel.com/hotlink/toc/id:kpDIPPRPF7/dipprproject-801-full/dippr-project-801-full.

[29] J.R. Rumble, CRC Handbook of Chemistry and Physics, 101st Edition, (2019), http://hbcponline.com/faces/contents/ContentsSearch.xht $\mathrm{ml}$.

[30] C.L. Yaws, Yaws' Handbook of Physical Properties for Hydrocarbons and Chemicals, (2008), https://app.knovel.com/hotlink/toc/id:kpYHPPHC0B/yaw s-handbook-physical/yaws-handbook-physical.

[31] J. Gau, D. Das, C. McEnally, D. Giassi, N. Kempema, M. Long, Yale Coflow Burner Information and CAD Drawings,

(2017),

https://doi.org/10.6084/m9.figshare.5005007.v1.

[32] M.J. Frisch, G.W. Trucks, H.B. Schlegel, G.E. Scuseria, M.A. Robb, J.R. Cheeseman, et al., Gaussian 16 Rev. C.01, Wallingford, CT, (2016),
[33] Y. Zhao, D.G. Truhlar, The M06 suite of density functionals for main group thermochemistry, thermochemical kinetics, noncovalent interactions, excited states, and transition elements: two new functionals and systematic testing of four M06-class functionals and 12 other functionals, Theor. Chem. Acc., 120 (2007) 215-241. [34] F. Weigend, Accurate Coulomb-fitting basis sets for H to Rn, Phys. Chem. Chem. Phys., 8 (2006) 1057-1065.

[35] F. Weigend, R. Ahlrichs, Balanced basis sets of split valence, triple zeta valence and quadruple zeta valence quality for H to Rn: Design and assessment of accuracy, Phys. Chem. Chem. Phys., 7 (2005) 3297-3305.

[36] G. Luchini, J.V. Alegre-Requena, I. Funes-Ardoiz, R.S. Paton, GoodVibes: automated thermochemistry for heterogeneous computational chemistry data, F1000Research, 9 (2020).

[37] P.C. St. John, Y. Guan, Y. Kim, S. Kim, R.S. Paton, Prediction of organic homolytic bond dissociation enthalpies at near chemical accuracy with sub-second computational cost, Nat Commun, 11 (2020) 2328.

[38] K. Fukui, The Path of Chemical-Reactions - the Irc Approach, Acc. Chem. Res., 14 (1981) 363-368.

[39] J.V. Alegre-Requena, S.V. Sowndarya, R. Pérez-Soto, T.M. Alturaifi, R.S. Paton, AQME v1.0, https://github.com/jvalegre/aqme, (2021),

[40] L.A. Curtiss, P.C. Redfern, K. Raghavachari, Gaussian-4 theory, J. Chem. Phys., 126 (2007) 084108.

[41] S. Grimme, Supramolecular binding thermodynamics by dispersion-corrected density functional theory, Chemistry - A European Journal, 18 (2012) 9955-9964.

[42] W. F. Bailey, A. S. Monahan, Statistical Effects and the Evaluation of Entropy Differences in Equilibrium Processes, J. Chem. Educ. , 55 (1978) 489-493.

[43] S. Patchkovskii, Brute Force Symmetry Analyzer, (2003), https://github.com/nquesada/symmetry.

[44] F. Roper, The prediction of laminar jet diffusion flame sizes: Part I. Theoretical model, Combust. Flame, 29 (1977) 219-226.

[45] L. Li, P.B. Sunderland, An improved method of smoke point normalization, Combust. Sci. Technol., 184 (2012) 829-841.

[46] D.D. Das, P.C. St. John, C.S. McEnally, S. Kim, L.D. Pfefferle, Measuring and predicting sooting tendencies of oxygenates, alkanes, alkenes, cycloalkanes, and aromatics on a unified scale, Combust. Flame, 190 (2018) 349-364. [47] Y. Kim, B.D. Etz, G.M. Fioroni, C.K. Hays, P.C. St. John, R.A. Messerly, et al., Investigation of structural effects of aromatic compounds on sooting tendency with mechanistic insight into ethylphenol isomers, Proc. Combust. Inst, 38 (2021) 1143-1151.

[48] C.S. McEnally, L.D. Pfefferle, Decomposition and hydrocarbon growth processes for hexadienes in nonpremixed flames, Combust. Flame, 152 (2008) 469481.

[49] T. Bierkandt, M. Hoener, N. Gaiser, N. Hansen, M. Köhler, T. Kasper, Experimental flat flame study of monoterpenes: Insights into the combustion kinetics of $\alpha$ pinene, $\beta$-pinene, and myrcene, Proc. Combust. Inst, 38 (2021) 2431-2440. 